\title{
Applications of Potassium Permanganate in the Oxidative Degradation of Trichloroethylene
}

\author{
Jude O. Ighere, Karina Honjoya, Ramesh C. Chawla \\ Chemical Engineering, Howard University, Washington DC, USA \\ Email: rchawla@howard.edu, jude.ighere@gmail.com
}

Received 2 May 2015; accepted 15 June 2015; published 18 June 2015

Copyright (C) 2015 by authors and Scientific Research Publishing Inc.

This work is licensed under the Creative Commons Attribution International License (CC BY).

http://creativecommons.org/licenses/by/4.0/

\section{Abstract}

The scope of this study was to determine techniques to remediate trichloroethylene contamination under different environmental conditions, media and in co-existence with chromium. The specific objectives were focused on the oxidation of trichloroethylene (TCE) in soil and aqueous media using both unmodified $\mathrm{KMnO}_{4}$ particles and poly (methyl methacrylate), PMMA encapsulated $\mathrm{KMnO}_{4}$ in the presence and absence of hexavalent chromium, $\mathrm{Cr}(\mathrm{VI})$. Molar ratios (p-values) of $\mathrm{KMnO}_{4}$ to TCE were used as a determining factor in the TCE oxidation process. p-values of 2, 5 and 10 were investigated in aqueous media and an approximately $0.5 \mathrm{M}^{-1} \cdot \mathrm{s}^{-1}$ rate constant was obtained using unmodified $\mathrm{KMnO}_{4}$ in aqueous system. The extent of oxidation did not change with TCE concentration. In soil system, TCE oxidation requires a large amount of $\mathrm{KMnO}_{4}$ to produce similar results as in aqueous system. pH experiments indicate that except at high alkaline condition, pH does not impact the extent of TCE oxidation. Also, the presence of $\operatorname{Cr}(\mathrm{VI})$ did not hinder TCE oxidation by $\mathrm{KMnO}_{4}$. Using controlled release application, the rate of TCE oxidation was reduced by $\mathrm{PMMA}$ encapsulated $\mathrm{KMnO}_{4}$. Comparative study indicated an expectedly slow rate of TCE degradation using modified $\mathrm{KMnO}_{4}$ but similar overall extent of oxidation for both modified and unmodified $\mathrm{KMnO}_{4}$. The application of the encapsulated matrix yielded $88 \% \pm 3 \%$ TCE oxidation and a simultaneous $81 \% \pm 2.1 \% \mathrm{Cr}$ (VI) reduction by ferrous ion in the same system.

\section{Keywords}

Trichloroethylene, Kinetics, Permanganate, Oxidation, Poly Methyl Methacrylate, Mixed Contaminants

\section{Introduction}

Chlorinated hydrocarbon in groundwater, soil and sludge is of global concern due to its high toxicity, stability

How to cite this paper: Ighere, J.O., Honjoya, K. and Chawla, R.C. (2015) Applications of Potassium Permanganate in the Oxidative Degradation of Trichloroethylene. Journal of Materials Science and Chemical Engineering, 3, 16-27.

http://dx.doi.org/10.4236/msce.2015.37003 
and widespread applications. In-situ chemical oxidation (ISCO) has been successfully used to degrade chlorinated hydrocarbons for decades [1] [2]. One of the popularly applied oxidants in ISCO is $\mathrm{KMnO}_{4}$ which may be due to its high oxidation potential across the $\mathrm{pH}$ meter [3]. Contaminants come in different species in hazardous waste sites. The mutual presence of organic and inorganic contaminants on several DOE sites is a complex problem in the design of degradation process. The co-existence of heavy metals and chlorinated hydrocarbon is common in most hazardous waste sites as included in the EPA National Priority List (NPL) (HazDat, 2007). A study by Joeng and Hayes in 2007 indicated that the rates and pathways of dechlorination of chlorinated hydrocarbons using other reducing agents were very well influenced by the presence of heavy metals [4].

Furthermore, oxidation of TCE and $\mathrm{Cr}(\mathrm{VI})$ by an oxidizing agent is by analogy the oxidation of TCE in the presence of $\mathrm{Cr}(\mathrm{VI})$; research has shown that TCE is dichlorinated in the presence of Fe(II) [5]. Therefore, combining the above two processes simultaneously could result in some undesirable products (e.g. vinyl chloride and $\mathrm{Cr}(\mathrm{VI})$ ). In the oxidation of TCE by permanganate in the presence of $\mathrm{Cr}(\mathrm{VI})$, there are perhaps two parallel reactions that can be proposed as described by Equations (1) and (2) below. However, the likely conversion in 2 is very low about $0.05 \%$ in soil [6].

$$
\begin{aligned}
& \mathrm{C}_{2} \mathrm{HCl}_{3}+2 \mathrm{KMnO}_{4} \rightarrow 2 \mathrm{MnO}_{2}+3 \mathrm{Cl}^{-}+\mathrm{H}^{+}+2 \mathrm{CO}_{2}(\mathrm{~g})+2 \mathrm{~K}^{+} \\
& 3 \mathrm{MnO}_{2}+4 \mathrm{Cr}(\mathrm{III}) \rightarrow 4 \mathrm{Cr}(\mathrm{VI})+3 \mathrm{Mn}+2 \mathrm{O}_{2}
\end{aligned}
$$

Huang et al. (2000) in a study indicated that while remediating dissolved-phase TCE could be rapid by introducing the appropriate oxidant, degradation of source zone (pure TCE) was very slow. This was explained as due to the slow mass transfer between the oxidant in aqueous phase and the pure TCE phase at the interface [7]. Thus the use of potassium permanganate with a high aqueous solubility of $64 \mathrm{~g} / \mathrm{L}$ at $20^{\circ} \mathrm{C}$ in TCE source zone (aqueous solubility of TCE is $1.28 \mathrm{mg} / \mathrm{L}$ ) would be much difficult. As a strong and reactive oxidant, $\mathrm{KMnO}_{4}$ would oxidize any reductive organic material dissolved in an aqueous medium. Hence the amount of $\mathrm{KMnO}_{4}$ available to oxidize the target contaminant is reduced thereby decreasing the oxidation efficiency. More $\mathrm{KMnO}_{4}$ than necessary is therefore used for complete degradation of the target compound [8]. Therefore, the availability of $\mathrm{KMnO}_{4}$ in aqueous phase can be controlled by slowing down its dissolution rate through encapsulation.

Permanganate is effective in ethylene oxidation because it is selective towards the double bond (functional group, $\mathrm{C}=\mathrm{C}$ ) [9]. Permanganate application in in-situ chemical oxidation of trichloroethylene results in $\mathrm{Cl}^{-}, \mathrm{CO}_{2}$, $\mathrm{H}^{+}$, and $\mathrm{MnO}_{2}$ or $\mathrm{Mn}^{2+}$. The $\mathrm{Mn}^{2+}$ is further oxidized to form $\mathrm{MnO}_{2}$ [10]. The formation of $\mathrm{MnO}_{2}$ or $\mathrm{Mn}^{2+}$ is a function of $\mathrm{pH}$ conditions of the system. According to Equations (3)-(6), the relative high oxidation potential of $\mathrm{KMnO}_{4}$ varies at different $\mathrm{pH}$ ranges.

$$
\begin{aligned}
& \mathrm{MnO}_{4}^{-}+\mathrm{e}^{-} \rightarrow \mathrm{MnO}_{4}^{2-}\left(\mathrm{E}^{0}=0.56 \mathrm{~V}, \mathrm{pH}>12\right) \\
& \mathrm{MnO}_{4}^{-}+3 \mathrm{e}^{-}+2 \mathrm{H}_{2} \mathrm{O} \rightarrow \mathrm{MnO}_{2}+4 \mathrm{OH}^{-}\left(\mathrm{E}^{0}=0.59 \mathrm{~V}, 3.5<\mathrm{pH}<12\right) \\
& \mathrm{MnO}_{4}^{-}+3 \mathrm{e}^{-}+2 \mathrm{H}^{+} \rightarrow \mathrm{MnO}_{2}+2 \mathrm{H}_{2} \mathrm{O}\left(\mathrm{E}^{0}=1.70 \mathrm{~V}, 3.5<\mathrm{pH}<12\right) \\
& \mathrm{MnO}_{4}^{-}+5 \mathrm{e}^{-}+8 \mathrm{H}^{+} \rightarrow \mathrm{Mn}^{2+}+4 \mathrm{H}_{2} \mathrm{O}\left(\mathrm{E}^{0}=1.51 \mathrm{~V}, \mathrm{pH}<3.5\right)
\end{aligned}
$$

Due to the different oxidation potential exhibited at different $\mathrm{pH}$ values, the pathway for TCE oxidation would vary (see Figure 3). Several intermediates are produced in this reaction. However, the final product remains that $\mathrm{CO}_{2}$ is produced [11]. Thus, the reaction between TCE and $\mathrm{KMnO}_{4}$ is very complex since it involves multiple intermediate steps and alternate pathways depending on $\mathrm{pH}$ of media. The overall reaction has been compressed into the forms in Equations (7) and (8) [11]-[13].

$$
\begin{aligned}
& \mathrm{C}_{2} \mathrm{HCl}_{3}+2 \mathrm{KMnO}_{4} \rightarrow 2 \mathrm{MnO}_{2}+3 \mathrm{Cl}^{-}+\mathrm{H}^{+}+2 \mathrm{CO}_{2}(\mathrm{~g})+2 \mathrm{~K}^{+} \\
& 5 \mathrm{C}_{2} \mathrm{HCl}_{3}+6 \mathrm{KMnO}_{4}+3 \mathrm{H}^{+} \rightarrow 6 \mathrm{MnO}_{2}+15 \mathrm{Cl}^{-}+10 \mathrm{CO}_{2}(\mathrm{~g})+2 \mathrm{~K}^{+}
\end{aligned}
$$

This reaction is even more complex in soil because of its natural organic and inorganic constituents that compete for the available oxidant. These non-target species not only consume the oxidant but may also result in complex reaction pathways possibly producing new contaminants [14].

Previous studies have concluded that TCE transformation by permanganate is pseudo-first-order with respect to both [TCE] and $\left[\mathrm{MnO}_{4}^{-}\right]$and second-order reaction overall (with a second order rate constant estimated 
between $640 \mathrm{mM}^{-1} \cdot \mathrm{s}^{-1}$ and $920 \mathrm{mM}^{-1} \cdot \mathrm{s}^{-1}$ ) [15] [16]. The expression for the second order rate law for the chemical oxidation of TCE by $\mathrm{MnO}_{4}^{-}$is described in Equation (9) [10]-[12] [17].

$$
\frac{\mathrm{d}[\mathrm{TCE}]}{\mathrm{d} t}=-k_{2}[\mathrm{TCE}]\left[\mathrm{MnO}_{4}^{-}\right]
$$

According to Urynowicz, if the concentration of $\mathrm{MnO}_{4}^{-}$does not change significantly with time (i.e. excess amount of $\mathrm{MnO}_{4}^{-}$), Equation (9) can be simplified to pseudo-first-order to (10) by defining the pseudo first-order rate constant as the product of the second order reaction rate constant and the initial concentration of $\mathrm{MnO}_{4}^{-}$.

$$
\frac{\mathrm{d}[\mathrm{TCE}]}{\mathrm{d} t}=-k_{1}[\mathrm{TCE}]
$$

where

$k_{1}=k_{2}\left[\mathrm{MnO}_{4}^{-}\right]=$pseudo first-order reaction rate constant $\left(\mathrm{s}^{-1}\right)$;

$k_{2}=$ second-order reaction rate constant $\left(\mathrm{M}^{-1} \cdot \mathrm{s}^{-1}\right)$;

$[\mathrm{TCE}]=$ concentration of the TCE $(\mathrm{M})$; and

$\left[\mathrm{MnO}_{4}^{-}\right]=$concentration of the $\mathrm{MnO}_{4}^{-}$.

However, another way of obtaining the data for second-order kinetics analysis and rate constant $(k)$ when $A$ reacts with $B$ as TCE and $\mathrm{KMnO}_{4}$ respectively is given as follows:

$$
\begin{gathered}
-r=-\frac{\mathrm{d} C_{\mathrm{A}}}{\mathrm{d} t}=-\frac{\mathrm{d} C_{B}}{\mathrm{~d} t}=k C_{A} C_{B} \\
-r_{A}=C_{A O} \frac{\mathrm{d} X_{A}}{\mathrm{~d} t}=k\left(C_{A O}-C_{A O} X_{A}\right)\left(C_{B O}-C_{A O} X_{A}\right)
\end{gathered}
$$

Let $M=C_{B O} / C_{A O}$ be the initial molar ratio of reactants, to obtain

$$
-r_{\mathrm{A}}=C_{A O} \frac{\mathrm{d} X_{\mathrm{A}}}{\mathrm{d} t}=k C_{A O}^{2}\left(1-X_{A}\right)\left(M-X_{A}\right)
$$

on separation and integration becomes

$$
\int_{0}^{X_{A}} \frac{\mathrm{d} X_{A}}{\left(1-X_{A}\right)\left(M-X_{A}\right)}=C_{A O} k \int_{0}^{t} \mathrm{~d} t
$$

After breaking down into partial fractions, integration, and rearrangement, the final result in a number of different forms is

$$
\ln \frac{M-X_{A}}{M\left(1-X_{A}\right)}=C_{A O}(M-1) k t=\left(C_{B O}-C_{A O}\right) k t \quad M \neq 1
$$

Thus, the second order rate law is expressed as

$$
\ln \frac{(M-X)}{M(1-X)}=\left(C_{B O}-C_{A O}\right) k t
$$

where $C_{A O}$ is the initial TCE concentration $(M)$; $C_{B O}$ is the initial $\mathrm{KMnO}_{4}$ concentration $(M) ; M=C_{B O} / C_{A O}$; $X$ is the TCE percent conversion, $X=\left(C_{A O}-C_{A t}\right) / C_{A O}$ and $C_{A t}$ is TCE concentration at time $t$.

Some researchers have only presented the kinetics of the process which basically depends on the data analysis and interpretation. However, both the extent and kinetics of the oxidation process better express the efficiency of remediation techniques. Therefore, the specific objectives of this paper focused on: 1) to determine the extent and kinetics of TCE degradation by $\mathrm{MnO}_{4}^{-} ; 2$ ) to determine the impact of $\mathrm{pH}$ on the extent of TCE degradation by $\mathrm{MnO}_{4}^{-}$; 3) to determine the effect of hexavalent chromium on TCE degradation by $\mathrm{MnO}_{4}^{-}$and 4) to investigate controlled oxidation rate by PMMA encapsulated $\mathrm{KMnO}_{4}$. 


\section{Materials and Methods}

\subsection{Chemical Preparation}

In this study, Trichloroethylene, 100\% (American Chemical Society, ACS grade), potassium permanganate (oxidant), sodium thiosulfate (used to quench reaction) and HPLC grade hexane (liquid-liquid extraction) were all purchased from Fisher Scientific. Bead particles of Poly (methymetacrylate) (PMMA) was ordered from Acros Organics; sodium borate and potassium dichromate purchased from Mallinckrodt, inc; Acetone (100\%) was purchased from Acros Organics. Stock solutions of trichloroethylene were prepared as necessary by adding pure phase TCE to continuously stirred Milli- $\mathrm{Q}^{\mathrm{TM}}$ deionized water in a glass flask using a 6000 arrow magnetic stirrer. Similarly stock solutions of TCE in hexane were likewise prepared for calibration and other applications. Stock solution of potassium permanganate was prepared at $1000 \mathrm{ppm}$ by adding $1000 \mathrm{mg}$ of $\mathrm{KMnO}_{4}$ particles to a liter of Milli- $\mathrm{Q}^{\mathrm{TM}}$ deionized water. While stock solution of sodium thiosulfate was prepared by adding sodium thiosulfate granules with Milli-Q ${ }^{\mathrm{TM}}$ deionized water. The stock solutions were stored in brown glass bottles and used fresh. Chelsea soil from Chelsea, Michigan was also used as received. Chelsea soil was spiked using a 40 $\mathrm{ml}$ amber vial with Teflon septa cover. $10 \mathrm{~g}$ of the soil was contaminated using a $30 \mathrm{ml}$ of 10,000 mg/l of TCE solution in hexane and mixed for 48 hours to equilibrate. After 48 hours, the unabsorbed TCE/Hexane phase was separated from the soil and analyzed to determine the amount of TCE left in equilibrium.

\subsection{Experimental Procedure}

Kinetics and extent experiment were performed in serial batch reactors of $40 \mathrm{ml}$ volatile organic analysis (VOA) vials with Teflon lined silicon septa. All experiments were performed at ambient temperature. Triplicate experiments were conducted for different molar ratios of TCE to $\mathrm{KMnO}_{4}(1: 2,1: 5$, and 1:10) using up to 12 vials per experiment. Aliquots of the oxidant were added to TCE solution in each vial, which were then closed tightly and mixed on a rotary mixer. At predetermined time intervals, $1 \mathrm{ml}$ the sodium thiosulfate, $\mathrm{NaS}_{2} \mathrm{O}_{3}$ solution were injected into the respective vials to quench the reaction and allow the analysis of TCE. Pure hexane of half the volume of sample solution was used to extract the TCE phase for analysis. Control vials containing only TCE solutions were analyzed at corresponding time intervals.

The extent of TCE degradation in soil system was also investigated at ambient temperature. $40 \mathrm{ml}$ VOA vials were used as the serial batch reactors. Each experimental run was performed in triplicates and a control experiment was performed without $\mathrm{MnO}_{4}^{-} \cdot \mathrm{MnO}_{4}^{-}$solutions were added to the $40 \mathrm{ml}$ vials containing $2 \mathrm{~g}$ of TCE spiked soil. The concentration of spiked soil from artificial contamination was $16.27 \pm 3.1 \mathrm{mg} / \mathrm{g}$. The vials containing a mixture of $\mathrm{MnO}_{4}^{-}$and TCE spiked soil were agitated continuously in a rotary mixer. At selected time intervals, sodium thiosulfate solution was injected into the appropriate vials and mixed to completely quench the reaction. Then, a predetermined volume of pure hexane was added to the sample, shaken for 2 minutes and then allowed to equilibrate for 10 minutes to extract the TCE residue. The hexane/TCE phase was therefore separated for TCE analysis on a gas chromatograph. The flow diagram for the experimental setup is shown in Figure 1.

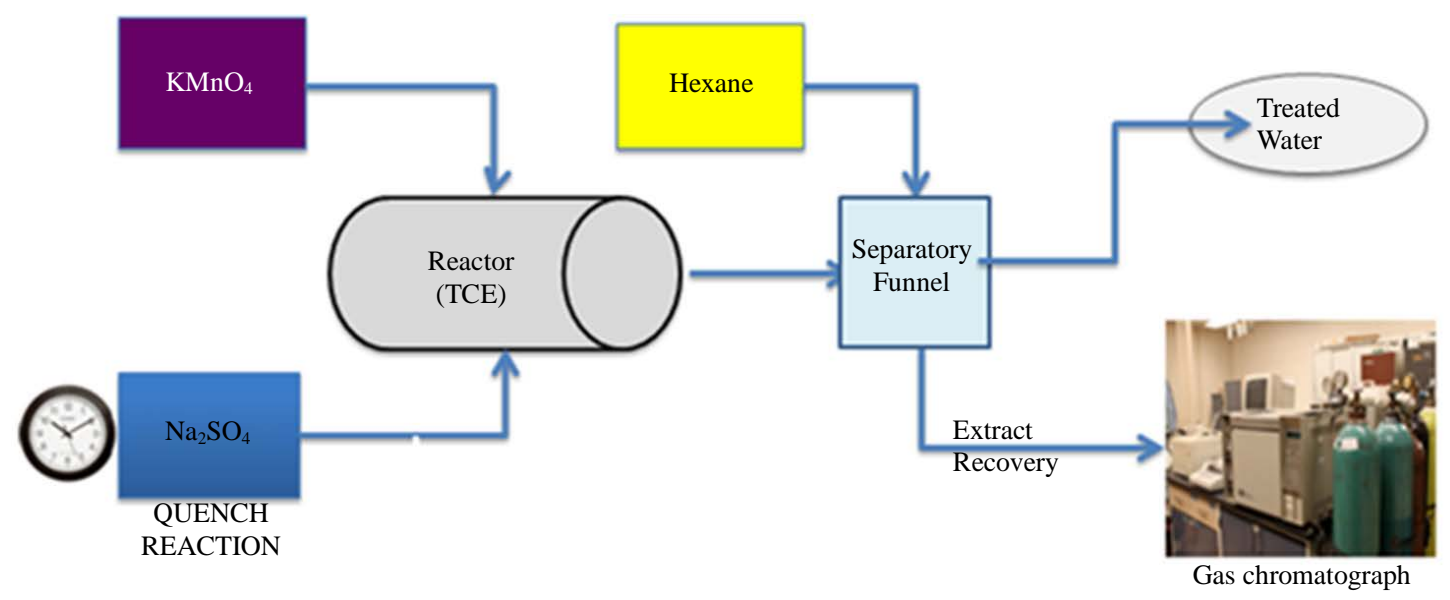

Figure 1. Process flow diagram for TCE degradation. 


\subsection{Encapsulation Procedure}

$\mathrm{KMnO}_{4}$ (oxidant) was encapsulated in PMMA matrix by adapting and modifying the molten suspension and cooling method at room temperature [18]. A predetermined amount (e.g. 2 g) of PMMA was measured into a $100 \mathrm{ml}$ beaker and $3 \mathrm{ml}$ acetone is added. The PMMA whose melting point is very high melts at room temperature under the influence of acetone. The molten PMMA is placed on a stirrer and mixed thoroughly using a glass magnetic arrow. Borax (Sodium Borate) was added to initiate cross-link of the molten PMMA. Under continuous mixing, particles of $\mathrm{KMnO}_{4}$ were added as required to produce 1:2, 1:4 and 1:8 of $\mathrm{KMnO}_{4}$ of PMMA ratio. After mixing for 10 mins to assume uniform particle dispersion, the molten mixture was allowed to solidify under room temperature by volatilizing acetone. Solidified particles/granules of encapsulated $\mathrm{KMnO}_{4}$ were reduced and used as needed for the release and reaction experiments. The flow diagram (Figure 2) depicts the encapsulation process.

\subsection{Analytical Procedure}

TCE Concentrations were measured using gas chromatograph, HP 5890 Series II with a fused silica capillary column. The detector was electron capture detector (ECD) as recommended for chlorinated hydrocarbon. $2 \mu l$ aliquot of the pre-extracted TCE in hexane was injected in the injection port. The concentration for the integrated area associated with the peak was evaluated on a calibration curve. For the analysis, the detector temperature was 220; injection port was 200 while oven (column) temperature was $150^{\circ} \mathrm{C}$. The primary carrier gas was helium gas supported by nitrogen gas to maintain pressure head.

$\mathrm{KMnO}_{4}$ concentrations were also measured to monitor the oxidant consumption rate. UV spectrophotometer (UV-166) set at $525 \mathrm{~nm}$ wavelength was used to measure $\mathrm{KMnO}_{4}$ concentrations (recommended by Hood et al, 2000). Calibration curve was obtained for concentration (absorbance) points in the domain of 0 to $100 \mathrm{mg} / \mathrm{l}$ $\mathrm{KMnO}_{4}$.

\section{Results and Discussion}

\subsection{Extent of TCE Degradation by $\mathrm{KMnO}_{4}$ in Aqueous and Soil Systems}

The complete oxidation of TCE, equivalently optimal amount of permanganate is required not merely stochiometric ratios as presented by Equations (3.1)-(3.4). Minimizing the amount of $\mathrm{MnO}_{2}$ produced from $\mathrm{KMnO}_{4}$

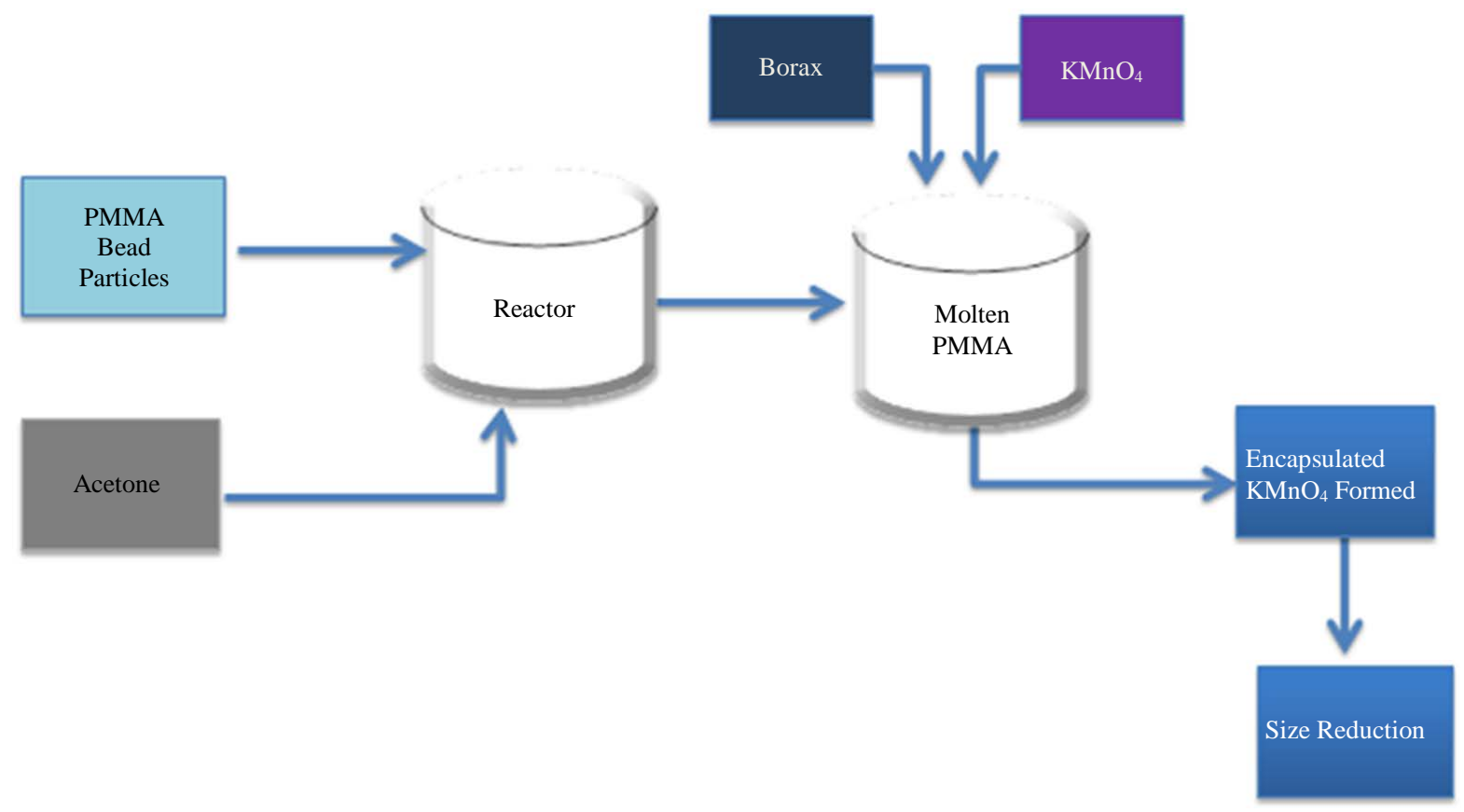

Figure 2. Encapsulation of $\mathrm{KMnO}_{4}$ using PMMA. 
is as important as the complete degradation of TCE. Therefore, the p-values help to determine the optimal $\mathrm{KMnO}_{4}$ to TCE ratio required without excess oxidant. Using an initial TCE concentration (Co) of 100 and 600 ppm with p-values of $0,2,5$, and 10, percent of TCE remaining was plotted against time. Result indicated that the higher p-value, the higher the extent of TCE degradation at equilibrium. When the initial TCE concentration was 100 ppm, for p values 2,5 , and 10 , the effluent was left with $48 \%, 0.6 \%$ and $0.03 \%$ TCE respectively at a reaction time of 180 mins (Figure 3). This shows that the optimal p-value is 10 but a p-value of 5 could be the optimal value depending on the allowable or maximum contaminant level in the region of operation. While for Concentration of $600 \mathrm{ppm}$, for p-values 2, 5, and 10, the effluent was left with 37.5\%, 0.021\% and $0.02 \%$ TCE respectively at a reaction time of 180 mins (Figure 4). The optimal p-value is clearly 5 because p-value of 10 would be excessive use of oxidant $\left(\mathrm{KMnO}_{4}\right)$.

\subsection{Influence of $\mathrm{pH}$ on the Extent of Reaction}

The impact of $\mathrm{pH}$ on the system is not largely significant at stochiometric molar ratios. However, at high alkaline $\mathrm{pH}$ of 12.05 the percent conversion for TCE oxidation is low compared to acidic conditions. This could be

Oxidation of TCE by $\mathrm{KMnO}_{4}$ in Aqueous System at Ambient Temperature

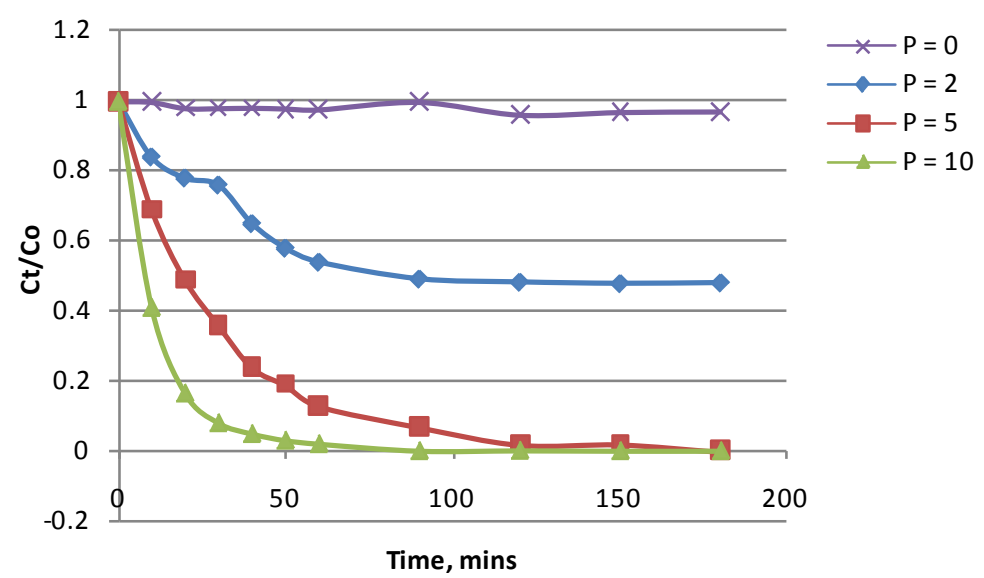

Figure 3. Extent (\%) of TCE oxidation as a function of time with varying p-values (Initial concentration $100 \mathrm{ppm}$ ).

Oxidation of TCE by $\mathrm{KMnO}_{4}$ in Aqueous System at Ambient Temperature

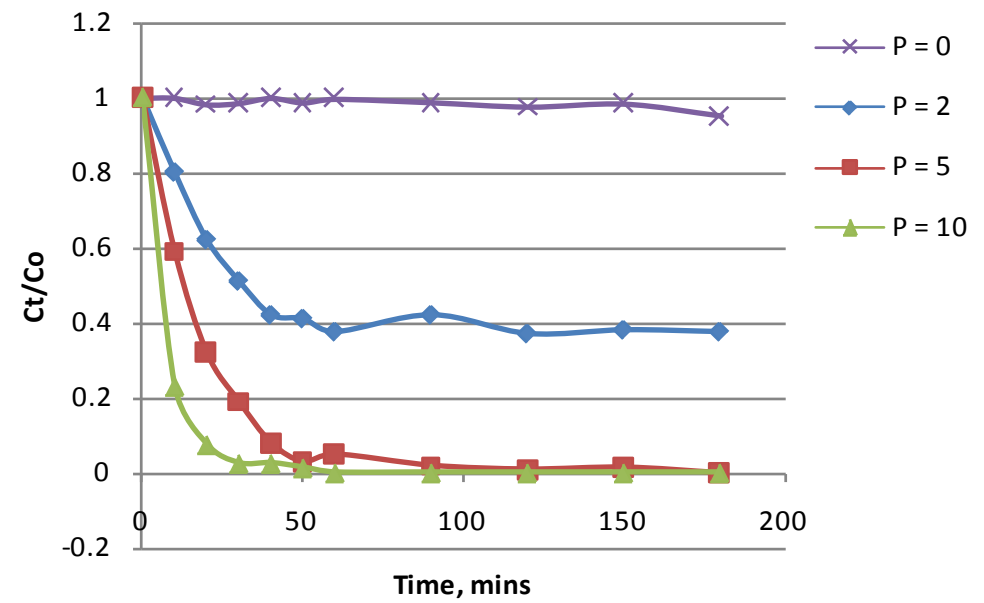

Figure 4. Extent (\%) of TCE oxidation as a function of time with varying $\mathrm{p}$-values (Initial concentration $\sim 600 \mathrm{ppm}$ ). 
attributed to the speciation or hydrolysis of $\mathrm{MnO}_{4}^{-}$to $\mathrm{MnO}_{2}$ under alkaline environments [11] [19]. The result in Figure 5 shows that $\mathrm{KMnO}_{4}$ is an effective oxidant across the $\mathrm{pH}$ range with slight variation likely due to speciation.

In soil systems, the efficiency of TCE degradation is very low. Only a small amount of TCE is degraded even after running the experiment for six hours. Other researchers proposed that this efficiency could even be lower for other types of soil such as clayey sand and silty-clay due to their pore sizes. In this study, a large amount of $\mathrm{KMnO}_{4}$ was used to obtain the similar TCE Degradation in 60 hours. For a molar ratio of TCE to $\mathrm{KMnO}_{4}$ of 1 to 5, 1 to 15 and 1 to 30, the percent TCE degraded were 62.8\%,96\%, and 99.3\% respectively after 2 days (Figure 6). This relatively lower TCE degradation rate in soil compared to aqueous system is attributed to the mass transfer limitation of the heterogeneous system.

\subsection{TCE Oxidation in the Presence of Cr(VI)}

TCE Oxidation by permanganate was not impacted by the presence of $\mathrm{Cr}(\mathrm{VI})$ possibly as both $\mathrm{KMnO}_{4}$ and $\mathrm{K}_{2} \mathrm{Cr}_{2} \mathrm{O}_{7}$ oxidizing agents although $\mathrm{KMnO}_{4}$ is a much stronger oxidant (Figure 7). Since $\mathrm{Cr}(\mathrm{VI})$ is the only or dominant species present in $\mathrm{K}_{2} \mathrm{Cr}_{2} \mathrm{O}_{7}$, therefore the primary oxidant is not consumed. Both $\mathrm{KMnO}_{4}$ and $\mathrm{K}_{2} \mathrm{Cr}_{2} \mathrm{O}_{7}$ are highly soluble in water and therefore equally occupy the oxidation interface. TCE oxidation by $\mathrm{KMnO}_{4}$ yielded $65.75 \%$ and $62.5 \%$ in the presence and absence of $\mathrm{Cr}(\mathrm{VI})$ respectively. This experiment was not investigated under varying $\mathrm{pH}$ conditions which could influence Chromium speciation in aqueous phase. This is consistent with the hypothesis and results from Woojin Lee, 2004.

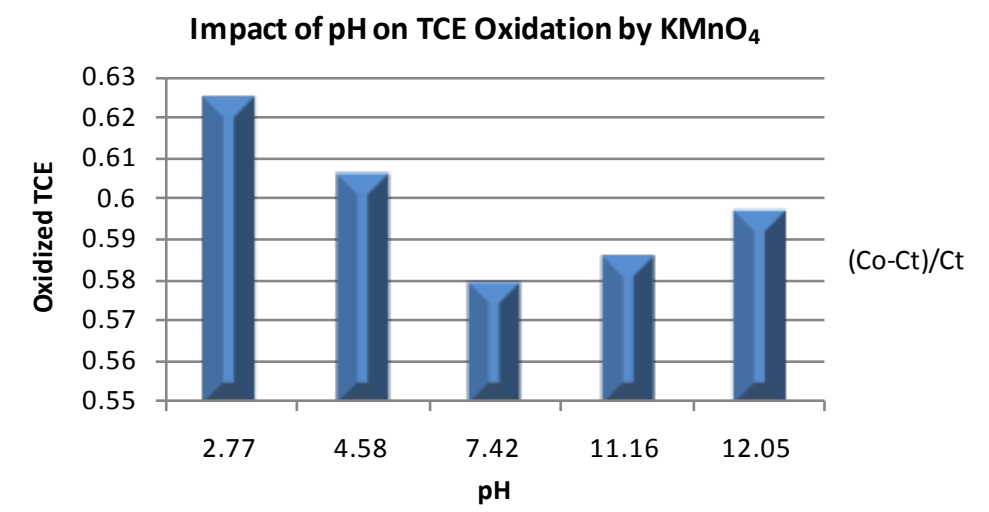

Figure 5. Influence of $\mathrm{pH}$ on the extent of TCE oxidation by $\mathrm{KMnO}_{4}$.

TCE Oxidation by Unmodified $\mathrm{KMnO}_{4}$ in Soil System in the Absence of $\mathrm{Cr}(\mathrm{VI})$

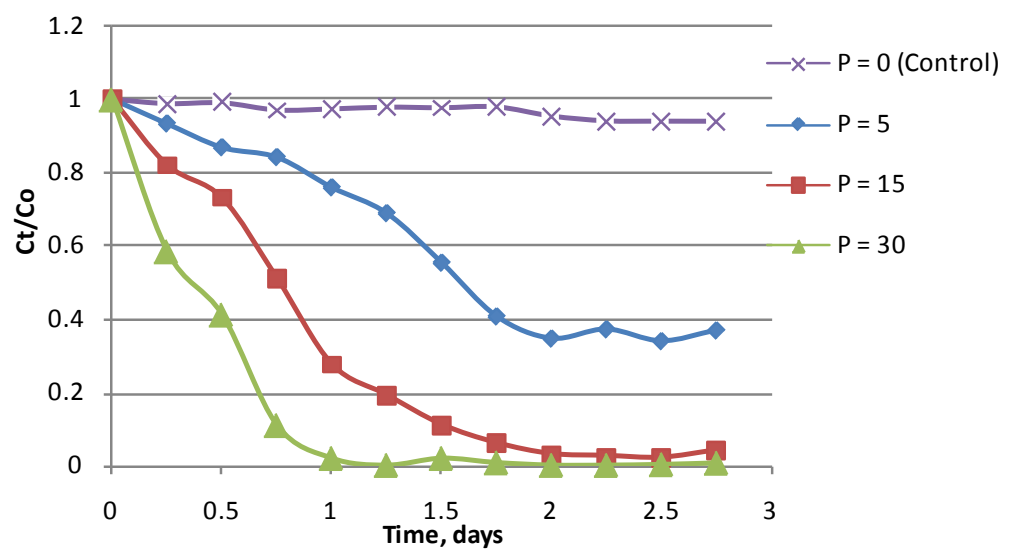

Figure 6. Extent (\%) of degradation initial TCE concentration $16.27 \mathrm{mg} / \mathrm{g}$ (using $2 \mathrm{~g}$ of soil) (Initial TCE $=0.25$ mmole). 


\subsection{Kinetics of TCE Degradation by $\mathrm{KMnO}_{4}$}

Figure 8 presents the plot of $\ln [(\mathrm{M}-\mathrm{X}) /(\mathrm{M}(1-\mathrm{X})]$ versus time for the $\mathrm{p}$ values of 2, 5, and 10 for an initial TCE concentration of $600 \mathrm{ppm}$. Following Equation (15), the second-order rate constants were calculated to be $441.67 \mathrm{mM}^{-1} \cdot \mathrm{s}^{-1}, 491.83 \mathrm{mM}^{-1} \cdot \mathrm{s}^{-1}$ and $496.4 \mathrm{mM}^{-1} \cdot \mathrm{s}^{-1}$ for $\mathrm{p}$ value 2,5 and 10 respectively. These $\mathrm{k}$-values are lower than the range $\left(600 \mathrm{mM}^{-1} \cdot \mathrm{s}^{-1}\right.$ to $\left.920 \mathrm{mM}^{-1} \cdot \mathrm{s}^{-1}\right)$ previously reported by other researcher [19] [20]. However, the near linear correlation indicated by the $\mathrm{R}^{2}$ values of $0.97,0.98$ and 0.995 for the respective $\mathrm{p}$-values implies a second-order overall reaction which had been reported [18] [20]. Therefore the differences in the rate constants can be attributed to equipment settings such as temperature of oven, injection and detector.

In soil system, the rate of the reaction is expectedly lower. Figure 9 presents the plot of $\ln [(\mathrm{M}-\mathrm{X}) /(\mathrm{M}(1-$ $\mathrm{X})$ ] versus time for the $\mathrm{p}$ values of 5,15 and 30 . For a second-order reaction rate analysis, $0.457 \mathrm{~kg} \cdot \mathrm{mole}^{-1} \cdot \mathrm{day}^{-1}$ $\left(5.287 \times 10^{-6} \mathrm{~kg} \cdot \mathrm{mole}^{-1} \cdot \mathrm{s}^{-1}\right), 0.651 \mathrm{~kg} \cdot \mathrm{mole}^{-1} \cdot \mathrm{day}^{-1}\left(7.54 \times 10^{-6} \mathrm{~kg} \cdot \mathrm{mole}^{-1} \cdot \mathrm{s}^{-1}\right)$ and $0.894 \mathrm{~kg} \cdot \mathrm{mole}^{-1} \cdot \mathrm{day}^{-1}(1.035$ $\times 10^{-6} \mathrm{~kg} \cdot \mathrm{mole}^{-1} \cdot \mathrm{s}^{-1}$ ) for the respective $\mathrm{p}$-values.

\subsection{Encapsulated $\mathrm{KMnO}_{4}$ in Aqueous Medium}

The oxidant release experiment was performed in aqueous phase. $\mathrm{KMnO}_{4}$ was released from PMMA encapsulation

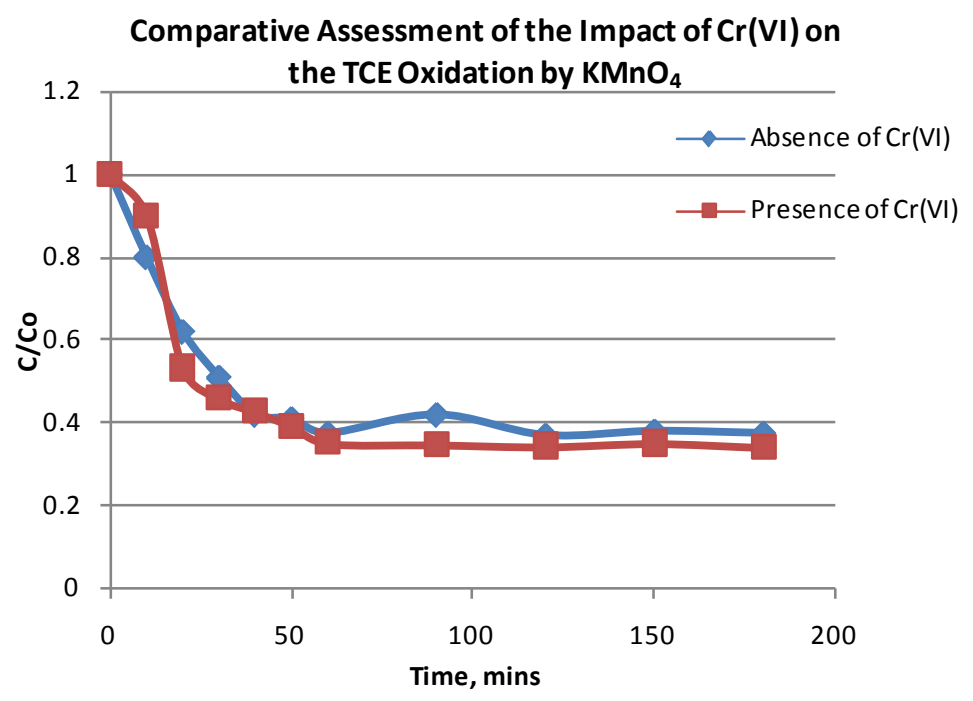

Figure 7. TCE oxidation by $\mathrm{KMnO}_{4}$ in the presence and absence of $\mathrm{Cr}(\mathrm{VI})$.

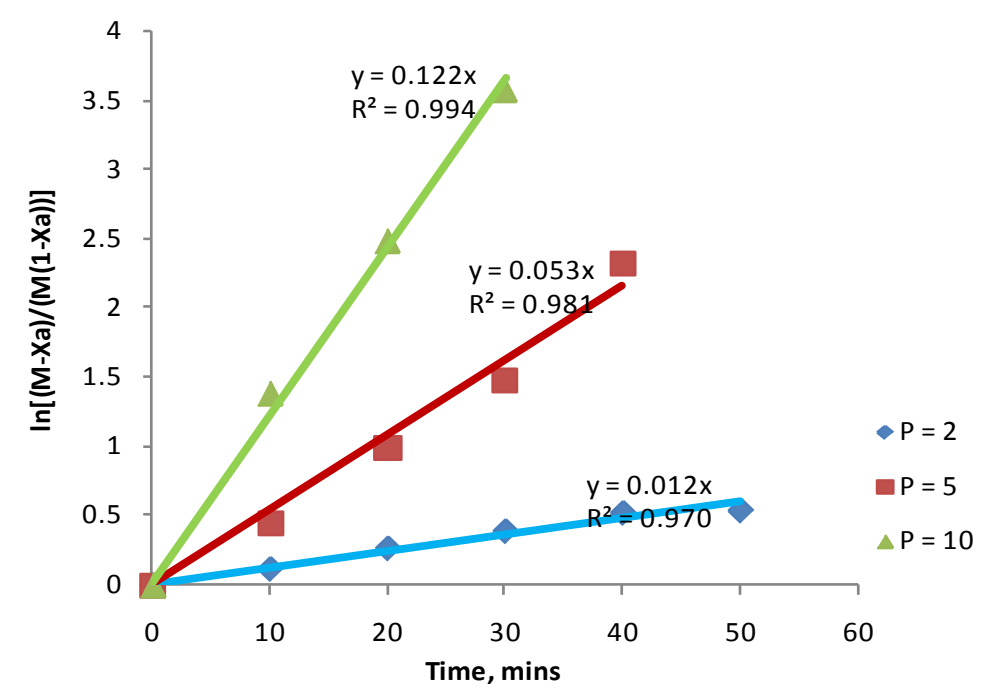

Figure 8. Kinetic analysis of TCE oxidation by $\mathrm{KMnO}_{4}$ in aqueous phase. 
in mass to mass ratios of 2:1, 4:1, and 8:1 of PMMA to $\mathrm{KMnO}_{4}$ respectively. The release profile indicates that efficiency of the oxidant release is inversely proportional to the mass ratio of PMMA to $\mathrm{KMnO}_{4}$. There was decrease in release with increased mass to mass ratio (see Figure 10). After a time period of 10 hours, 79\%, 55.35\% and $33.59 \%$ of $\mathrm{KMnO}_{4}$ has been released from 2:1, 4:1, and 8:1 encapsulated matrix respectively. PMMA is not readily soluble in aqueous medium hence initial release near time $t=0$ could be attributed to dissolution of $\mathrm{KMnO}_{4}$ integrated on outer surface of encapsulated matrix. Results showed the lowest release rate is associated with 8:1 mass ratio likely due to the thickness of the PMMA layer in the encapsulated matrix.

\subsection{TCE Oxidation by PMMA Modified $\mathrm{KMnO}_{4}$ Simultaneously with $\mathrm{Cr}(\mathrm{VI})$ Reduction by $\mathrm{FeSO}_{4}$}

The Cr(VI) reduction by ferrous ion still shows its initial rapid reaction which stops on the accumulation of precipitate. There was $81 \% \mathrm{Cr}(\mathrm{VI})$ reduced and $88 \%$ TCE oxidized by ferrous ion and permanganate respectively (Figure 11). This result compares to the result obtained for the independent redox reactions of TCE oxidation by $\mathrm{KMnO}_{4}$ (see Figure 3 and Figure 4). This could be attributed to the fact that PMMA dissolves in TCE but not

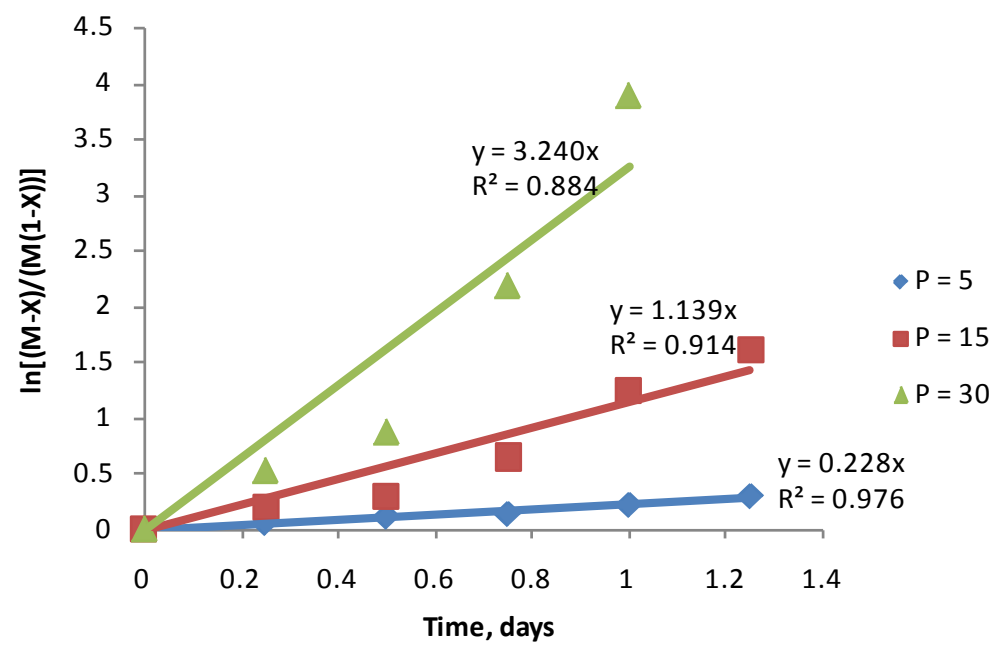

Figure 9. Kinetic analysis of TCE oxidation by $\mathrm{KMnO}_{4}$ in chelsea soil.

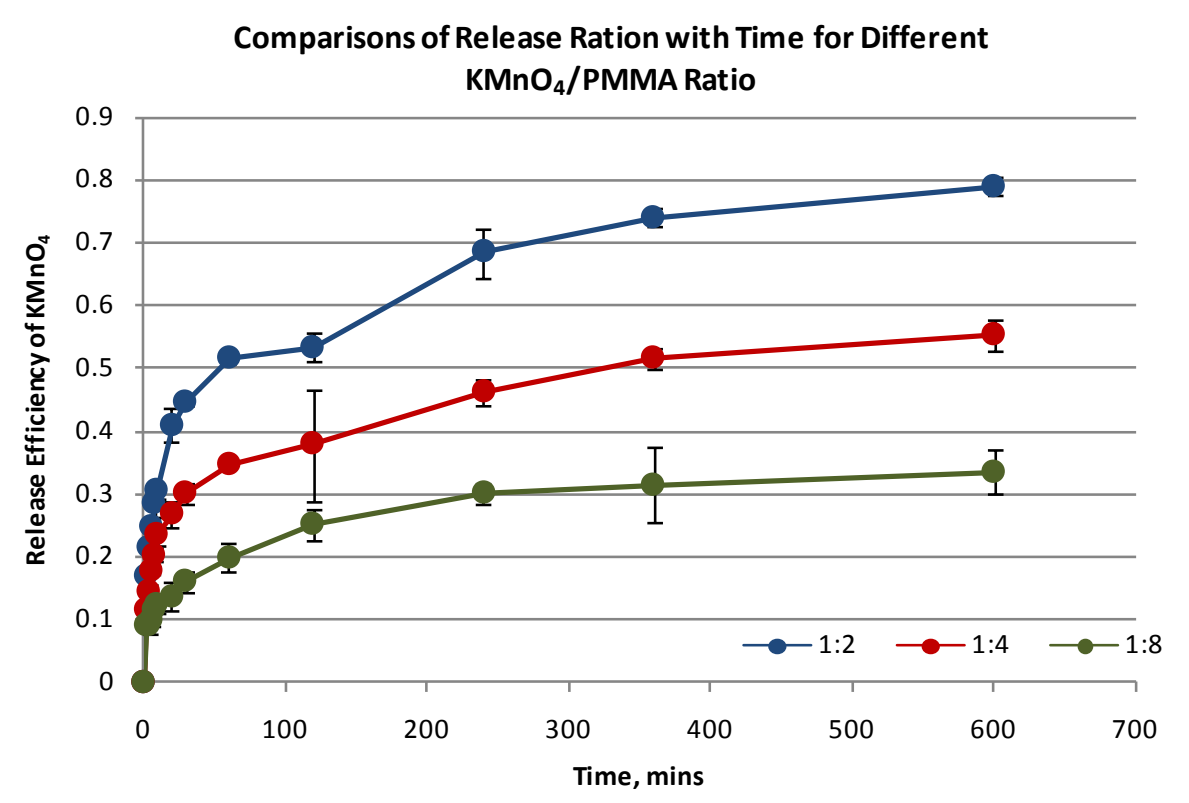

Figure 10. Release profile of $\mathrm{KMnO}_{4}$ from PMMA encapsulation. 
in water. Therefore on continuous interaction with TCE molecules the layers of PMMA could wear off from matrix releasing more $\mathrm{KMnO}_{4}$ on contact. The availability of the oxidant depends on the dissolution and diffusion from layers of PMMA on contact with the TCE.

The efficiency of TCE degradation using PMMA modified $\mathrm{KMnO}_{4}$ and unmodified $\mathrm{KMnO}_{4}$ as function of time was plotted in Figure 12. The release rate for $\mathrm{KMnO}_{4}$ from the encapsulated matrix into aqueous phase is expectedly slow which influences the rate of TCE oxidation.

\section{Conclusions}

The optimal concentration of oxidant required for TCE oxidation depends on the investigated p-values to prevent secondary contamination from using excess $\mathrm{KMnO}_{4}$. The overall reaction implied second-order kinetics with near linear correlation indicated by $\mathrm{R}$ square values. The estimated efficiency or extent of oxidation increased with increased p-values. The extent of the reaction is not largely influenced by $\mathrm{pH}$ conditions. However, at alkaline media there is relatively lower efficiency attributed to manganese oxide particles deposited at the oxidation interface. The presence of $\mathrm{Cr}(\mathrm{VI})$ does not affect TCE oxidation by $\mathrm{KMnO}_{4}$ in aqueous phase. Both

Simultaneous Degradation of Mixed TCE and $\mathrm{Cr}(\mathrm{VI}) \mathrm{Using}^{\mathrm{FeSO}} \mathrm{S}_{4}$ and PMMA Coated $\mathrm{KMnO}_{4}$

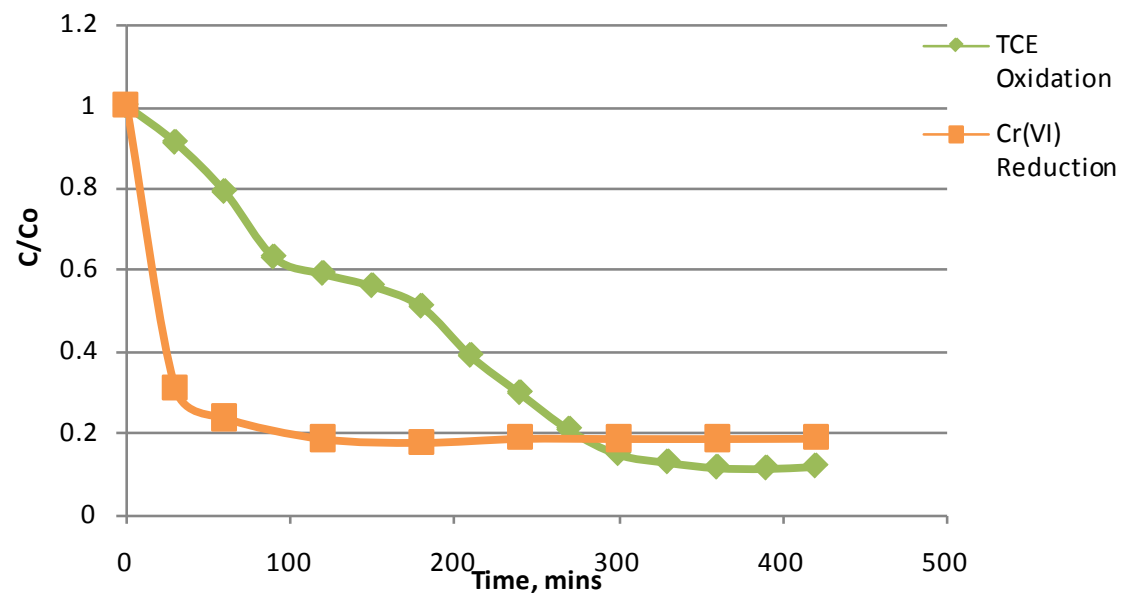

Figure 11. Degradation of mixed TCE and $\mathrm{Cr}(\mathrm{VI})$ contaminants using modified $\mathrm{KMnO}_{4}$.

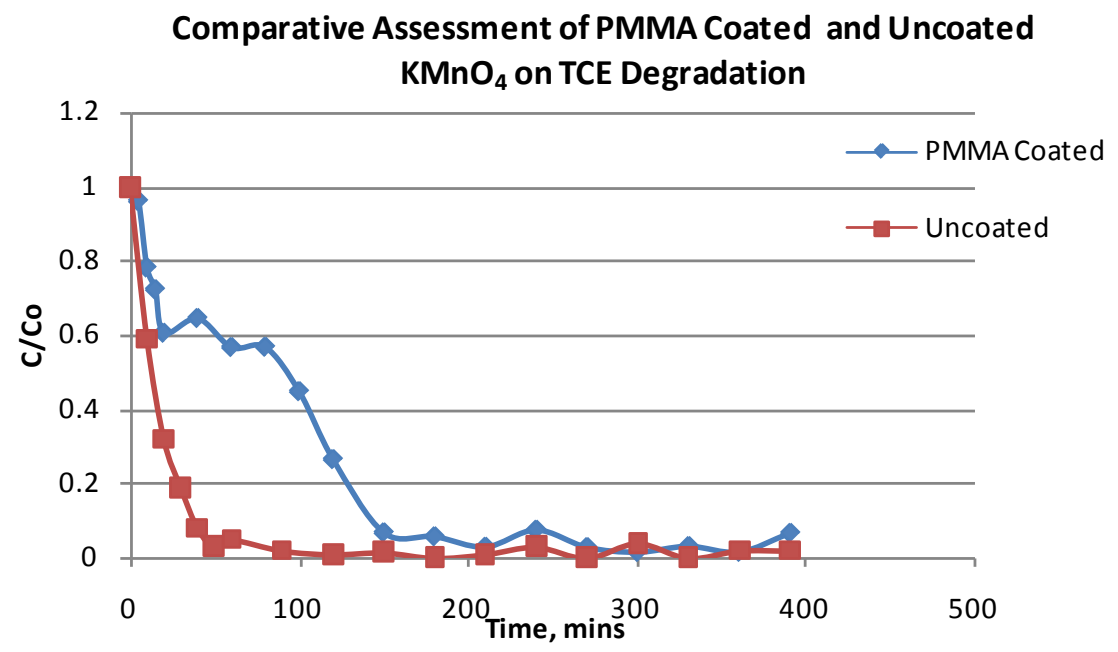

Figure 12. Degradation of mixed TCE and $\mathrm{Cr}(\mathrm{VI})$ contaminants using unmodified $\mathrm{KMnO}_{4}$. 
$\mathrm{KMnO}_{4}$ and $\mathrm{K}_{2} \mathrm{Cr}_{2} \mathrm{O}_{7}$ are oxidizing agents and highly soluble in water. This could be responsible for the result obtained as both equally occupy the aqueous-TCE oxidation interface. In soil systems, the degradation is slower due to imposed mass transfer resistance and hence increased oxidant consumption.

PMMA was effective in controlling the instant dissolution of $\mathrm{KMnO}_{4}$ in aqueous media. The release rate depends on the thickness of the PMMA layer on oxidant surface. Results showed that the encapsulation of $\mathrm{KMnO}_{4}$ by PMMA using the modified molten suspension technique controlled the rate of dissolution of $\mathrm{KMnO}_{4}$ and improved the selective interaction between TCE and the $\mathrm{KMnO}_{4}$. The amount of TCE oxidized increased in mixed contaminant degradation but at much longer time to achieve similar result unmodified $\mathrm{KMnO}_{4}$. Thus, the PMMA encapsulated $\mathrm{KMnO}_{4}$ can be used to target TCE in a mixed contamination. This study provides insight into the use of PMMA for different applications 1) for oxidant persistence in the long-term contamination problem of TCE; 2) for improved preferential interaction of oxidant with target contaminant based on environmental responsive condition.

\section{References}

[1] Huang, K.C., Hoag, G.E., Chheda, P., Woody, B.A. and Dobbs, G.M. (1999) Kinetic Study of the Oxidation of Trichloroethylene by Potassium Permanganate. Environmental Engineering Science, 16, 265-274.

[2] Kirschling, T.L., Gregory, K.B., Minkley, E.G., Lowry, G.V. and Tilton, R.D. (2010) Impact of Nanoscale Zero-Valent Iron on Geochemistry and Microbial Populations in trichloroethylene Contaminated Aquifer Materials. Environmental Science \& Technology, 44, 3474-3480. http://dx.doi.org/10.1021/es903744f

[3] Crimi, M.L. and Siegrist, R.L. (2005) Factors Affecting Effectiveness and Efficiency of DNAPL Destruction Using Potassium Permanganate and Catalyzed Hydrogen Peroxide. Journal of Environmental Engineering (ASCE), 131, 1724-1732. http://dx.doi.org/10.1061/(ASCE)0733-9372(2005)131:12(1724)

[4] Jeong, H.Y. and Hayes, K.M. (2007) Reductive Dechlorination Tetrachloroethylene by Mackinawite (FeS) in the Presence of Metals: Reaction Rates. Environmental Science and Technology, 41, 6390-6396. http://dx.doi.org/10.1021/es0706394

[5] Lee, W. (2004) Removal of Trichloroethylene in Reduced Soil Columns. Journal of Hazardous Materials, 113, 175-180.

[6] Apte, A.M., Tare, V. and Bose, P. (2006) Extent of oxidation of Cr(III) to Cr(VI) under Various Conditions Pertaining to Natural Environment. Journal of Hazardous Materials, 128, 164-174.

[7] Huang, K.C., Hoag, G.E., Chheda, P., Woody, B.A. and Dobbs, G.M. (2000) A Pilot Scale Study of Oxidation of Trichloroethylene by Sodium Permanganate. Proceedings of the 2nd International Conference on Remediation of Chlorinated and Recalcitrant Compounds, Monterey, 145-152.

[8] Yuan, B., Chen, Y. and Fu, M.-L. (2012) Degradation Efficiencies and Mechanisms of Trichloroethylene (TCE) by Controlled-Release Permanganate (CRP) Oxidation. Chemical Engineering Journal, 192, 276-283.

[9] Singh, N. and Lee, D.G. (2001) Permangante: A Green and Versatile Industrial Oxidant. Organic Process Research and Development, 5, 599-603. http://dx.doi.org/10.1021/op010015x

[10] Kao, C.D., Huang, K.D., Wang, J.Y., Chena, T.Y. and Chien, H.Y. (2008) Application of Potassium Permanganate as an Oxidant for in Situ Oxidation of Trichloroethylene-Contaminated Groundwater: A Laboratory and Kinetics Study. Journal of Hazardous Materials, 153, 919-927.

[11] Seol, Y. and Schwartz, F.W. (2000) Phase-Transfer Catalysis Applied to the Oxidation of Nonaqueous Phase Trichloroethylene by Potassium Permanganate. Journal of Contaminant Hydrology, 44, 185-201. http://dx.doi.org/10.1016/S0169-7722(00)00093-0

[12] Hood, E.D., Thomson, N.R., Grossi, D. and Farquhar, G.J. (2000) Experimental Determination of the Kinetic Rate Law for the Oxidation of Perchloroethylene by Potassium Permanganate. Chemosphere, 40, 1383-1388. http://dx.doi.org/10.1016/S0045-6535(99)00278-7

[13] Freedman, F and Kappos, J.C. (1985) Permanganate ion Oxidations: 15. Additional Evidences of Formation of Soluble (Colloidal) Manganese Dioxide during the Permanganate Ion Oxidation of Carbon-Carbon Double Bonds in Phosphate-Buffered solutions. Journal of the American Chemical Society, 107, 6628-6633. http://dx.doi.org/10.1021/ja00309a034

[14] Huang, K.-C., Hoag, G.E., Chheda, P., Woody, B.A. and Dobbs, G.M. (2002) Chemical Oxidation of Trichloroethylene with Potassium Permanganate in a Porous Medium. Advances in Environmental Research, 7, 217-229. http://dx.doi.org/10.1016/S1093-0191(01)00122-8

[15] Yan, Y.E. and Schwartz, F.W. (2000) Kinetics and Mechanisms for TCE Oxidation by Permanganate. Environmental Science \& Technology, 34, 2535-2541. http://dx.doi.org/10.1021/es991279q 
[16] Yan, Y.E. and Schwartz, F.W. (1999) Oxidative Degradation and Kinetics of Chlorinated Ethylenes by Potassium Permanganate. Journal of Contaminant Hydrology, 37, 343-365. http://dx.doi.org/10.1016/S0169-7722(98)00166-1

[17] Urynowicz, M.A. (2008) In Situ Chemical Oxidation with Permanganate: Assessing the Competitive Interactions between Target and Nontarget Compounds. Soil \& Sediment Contamination, 17, 53-62. http://dx.doi.org/10.1080/15320380701741412

[18] Kang, N., Hua, I., Suresh, P. and Rao, C. (2004) Production and Characterization of Encapsulated Potassium Permanganate for Sustained Release as an in Situ Oxidant. Industrial \& Engineering Chemistry Research, 43, 5187-5193. http://dx.doi.org/10.1021/ie0499097

[19] Huang, K., Hoag, G.E., Chheda, P., Woody, B.A. and Dobbs, G.M. (2001) Oxidation of Chlorinated Ethenes by Potassium Permanganate: A Kinetics Study. Journal of Hazardous Materials, 87, 155-169.

[20] Urynowicz, M.A. and Siegrist, R.L. (2005) Interphase Mass Transfer during Chemical Oxidation of TCE DNAPL in an Aqueous System. Journal of Contaminant Hydrology, 80, 93-106. http://dx.doi.org/10.1016/j.jconhyd.2005.05.002 